\title{
Experimental research on the instantaneous and long-term deflections of pre-cracked concrete beams enhanced by carbon fibre reinforced polymer
}

\author{
Shiyong Jiang, Tao Cai, Shijuan Wu, Weilai Yao \\ Department of Military facilities, Army Logistics University of PLA, Chongqing 401331, China \\ jiangshiy@163.com,Caita05474@foxmail.com,wudzon@163.com,futureYWL@hotmail.com
}

\begin{abstract}
This paper aims to disclose the influence law of cracks on instantaneous and long-term deflections of reinforced beam. For this purpose, four concrete beams were created, pre-loaded to varied degrees of cracking, and reinforced with carbon fibre reinforced polymer (CFRP). Then, a 300-day load test was carried out on these samples to measure the instantaneous and long-term deflections. The experimental results show that the pre-cracking degree has little influence on instantaneous deflection; whether a beam is precracked or intact, the final deflection of the beam is mostly affected by its initial deflection before the reinforcement; the pre-cracking degree is negatively correlated to the magnitude of additional deflection under sustained load. The research findings lay the basis for judging whether a reinforced beam can be used normally in the long run.
\end{abstract}

KEYwORDS. Carbon fibre reinforced polymer (CFRP); Pre-cracked beams; Creep; Long-term deflection.

\section{OPEN ACCESS}

Citation: S.Y. Jiang, T. Cai, S.J. Wu, W.L. Yao, Experimental research on the instantaneous and long-term deflections of pre-cracked concrete beams enhanced by carbon fibre reinforced polymer, Frattura ed Integrità Strutturale, 46 (2018) 275-284.

Received: 31.05 .2018

Accepted: 12.07 .2018

Published: 01.10 .2018

Copyright: $\mathbb{2} 2018$ This is an open access article under the terms of the CC-BY 4.0, which permits unrestricted use, distribution, and reproduction in any medium, provided the original author and source are credited.

\section{INTRODUCTION}

$\mathrm{T}$ hanks to its light weight, high strength and good corrosion resistance, carbon fibre reinforced polymer (CFRP) has been widely used to strengthen and reinforce concrete structures [1]. For instance, the reinforcement of flexural members (beams) with CFRP plate is now a common engineering practice. The CFRP reinforcement can greatly improve the short-term beam performance, e.g. the ultimate bearing capacity [2 5]. In the long run, however, it is inevitable for concrete and other materials of the beam to creep under external load. The resulting deflection of the beam will accumulate over time, and eventually surpass the limit state of normal use. Thus, the reinforced beam cannot satisfy safety requirements after long-term use.

At present, the long-term deformation behaviours of reinforced beam have not been extensively studied at home or abroad. There are a few studies on directly reinforced beams with no initial crack or deformation. For example, Nikolaos Plevris et al. [6] investigated the effect of fibre reinforced plastic (FRP) on long-term beam deflection through a 250-day load test on various fibre-reinforced concrete beams. Sungnam Hong et al. [7] conducted a 550-day creep experiment on three concrete beams, namely, concrete beams reinforced by the CFRP, concrete beams enhanced by glass fibre reinforced polymer 
(GFRP) and unreinforced concrete beams. During the experiment, each kind of concrete beams was piled up to withstand the external load. El-Sayed A.K. et al. [8] performed a bearing capacity test on two flat beams and a 600-day creep test on three CFRP-reinforced flat beams. Tan K.H. [9] carried out a 2 year-long creep test on six reinforced concrete beams partially reinforced by the GFRP and three reinforced concrete beams. During the test, the load was adjusted to different levels, and the beams were reinforced to varied degrees. Kim [10] carried out a 300-day load test on a GFRP-reinforced beam and a CFRP-reinforced beam, and measured the beam deflection, concrete strain, internal rebar strain, and FRP strain during the loading. All the above long-term load tests show that the ultimate deflection of directly reinforced beam with no cracks directly hinges on the level of external load and the degree of reinforcement, and that the long-term deflection can be partially constrained by the reinforcement (e.g. CFRP and GFRP).

In practice, directly reinforced intact beam is very rare. Most beams are already cracked before reinforcement due to previous use. Nevertheless, there is very limited report on the long-term deformation behaviours of reinforced beams with cracks prior to reinforcement (pre-cracked reinforced beam). Through a relaxation test on three pre-cracked reinforced concrete beams, M. Muller [11] disclosed the negative correlation between the number of initial cracks and the additional beam deflection after the reinforcement. Rao Xinpin [12] from Hunan University was the only scholar in China that explored the long-term deflection of initially deformed reinforced concrete beams. During Rao's research, two reinforced concrete beams were loaded to the same level; one of them was reinforced with the CFRP after its deformation, while the other was directly taken as the control. Then, long-term observation was made without changing the load. The research shows that the CFRP has little impact on long-term beam deflection, but fails to describe the crack condition of the beams. To sum up, the research into the long-term deformation of reinforced beams, especially pre-cracked ones, is severely insufficient.

To make up for the gap, this paper attempts to disclose the effect of cracks on instantaneous and long-term deflections of reinforced beams. For this purpose, four concrete beams were created, pre-loaded to varied degrees of cracking, and reinforced with the CFRP. Then, a long-term load test was carried out on these samples. The innovation of this research is based on practical engineering, and the cracks in concrete beams are considered in the test. In order to explore the effects of damage of concrete beams on the instantaneous and long-term deformation of reinforced beams. The research findings provide a valuable reference for actual reinforcement projects.

\section{EXPERIMENTAL STUDY}

\section{]}

Test parameters $\mathrm{n}$ our research, the CFRP plates are $100 \mathrm{~mm}$-wide and $1.4 \mathrm{~mm}$-thick adhesive plates with a tensile strength of $2,482 \mathrm{MPa}$, an elastic modulus of $174 \mathrm{GPa}$, and an ultimate elongation of $1.68 \%$. The elastic modulus of the structural adhesive is 3.5GPa. The reinforcements are all made of HPB400 steel. Specifically, the diameter, tensile strength and elastic modulus are respectively $28 \mathrm{~mm}, 456 \mathrm{MPa}$ and $200 \mathrm{GPa}$ for compressive bars, $14 \mathrm{~mm}, 461 \mathrm{MPa}$ and $200 \mathrm{GPa}$ for tensile bars, and $8 \mathrm{~mm}, 457 \mathrm{MPa}$ and $200 \mathrm{GPa}$ for stirrups.

The concrete for the test beams was supplied by a local commercial concrete mixing station. It was casted into a batch of $150 \mathrm{~mm} \times 150 \mathrm{~mm} \times 300 \mathrm{~mm}(\mathrm{~L} \times \mathrm{W} \times \mathrm{H})$ standard prismatic specimens, turned into test beams, and cured together before the experiment. On the day of experiment, the compressive strength and elastic modulus of the prismatic concrete specimens were measured as $41.9 \mathrm{MPa}$ and $33.38 \mathrm{GPa}$, respectively.

\section{Sample design}

Four identical reinforced concrete beams, denoted as B-1, B-2, B-3 and B-4, were prepared for the experiments. All four beams are 3,300 $\mathrm{mm}$ long, $250 \mathrm{~mm}$ wide and $400 \mathrm{~mm}$ tall. The details of the beams and reinforcement are given in Fig. 1. Note that a high reinforcement ratio was adopted for the beams so that the concrete edge can withstand the compressive strain under heavy external load (maximum compressive strain $\leq(0.4 \sim 0.5) \mathrm{fc}$ ). In this case, the creep of the concrete always falls in the range of linear creep [13]. The stirrups were dandified at both ends of the support to eliminate shearing failure in the long-term experiment. To prevent delamination of CRFP plates, the key anchoring length of these plates were kept constant during the reinforcement, and stirrups were provided at both ends of each CFRP plate [14].

\section{Experimental procedure}

Let Fu be the ultimate bearing capacity of the test beams before reinforcement. After curing, the four-point bending method was adopted to apply 15\% Fu, 45\% Fu and 65\% Fu onto B-2, B-3 and B-4, respectively (pre-loading), The B-1 beam is not preloaded as a contrast beam for the test, and the midspan deflection and sectional crack development were recorded for each beam. Then, the load was removed (unloading), and the four test beams were reinforced and cured as per the above 
plan. After curing, the ultimate load of $75 \% \mathrm{Fu}$ was applied onto all the four beams (final loading) and maintained at that level (sustained loading). The midspan deflection and crack development of each beam were recorded periodically, together with the lab temperature and humidity.

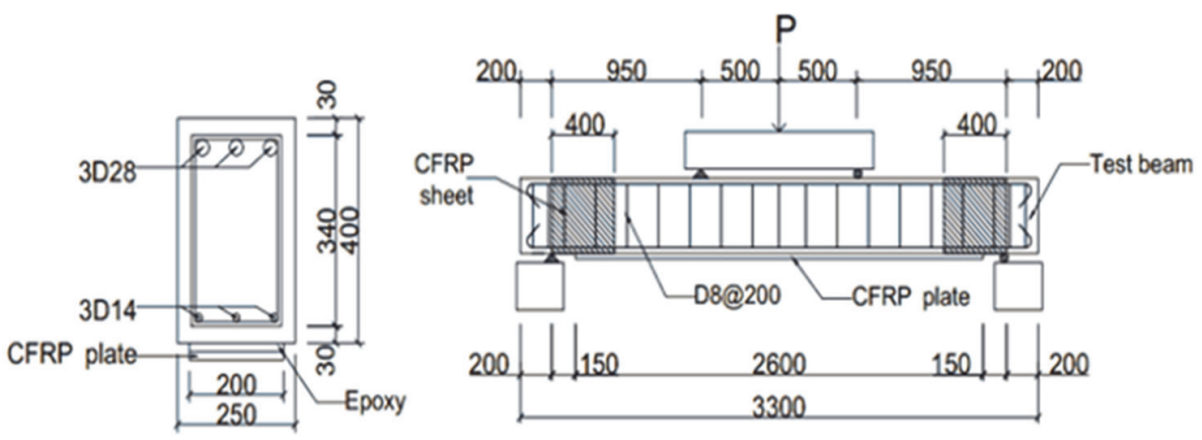

Figure 1: Details of the test beams and reinforcement.

\section{EXPERIMENTAL RESULTS}

\section{Pre-loading}

o reflect the actual conditions of reinforcement, the beams were cracked under pre-loading prior to reinforcement. The pre-loading process is illustrated in Fig. 2, Fig. 3 and Tab. 1.

L As shown in Fig. 2, the loading device for pre-loading and long-term load holding consists of a reaction beam connected to the trench, a hand-type mechanical jack, a force sensor and a distribution beam. The magnitude of the applied load can be displayed in real time on the force sensor between the mechanical jack and the reaction beam. The mechanical jack was selected to meet the load requirements of long-term load holding. Overall, the loading device is easy to isntall and operate, flexible in loading and unloading, and stable in the long term.

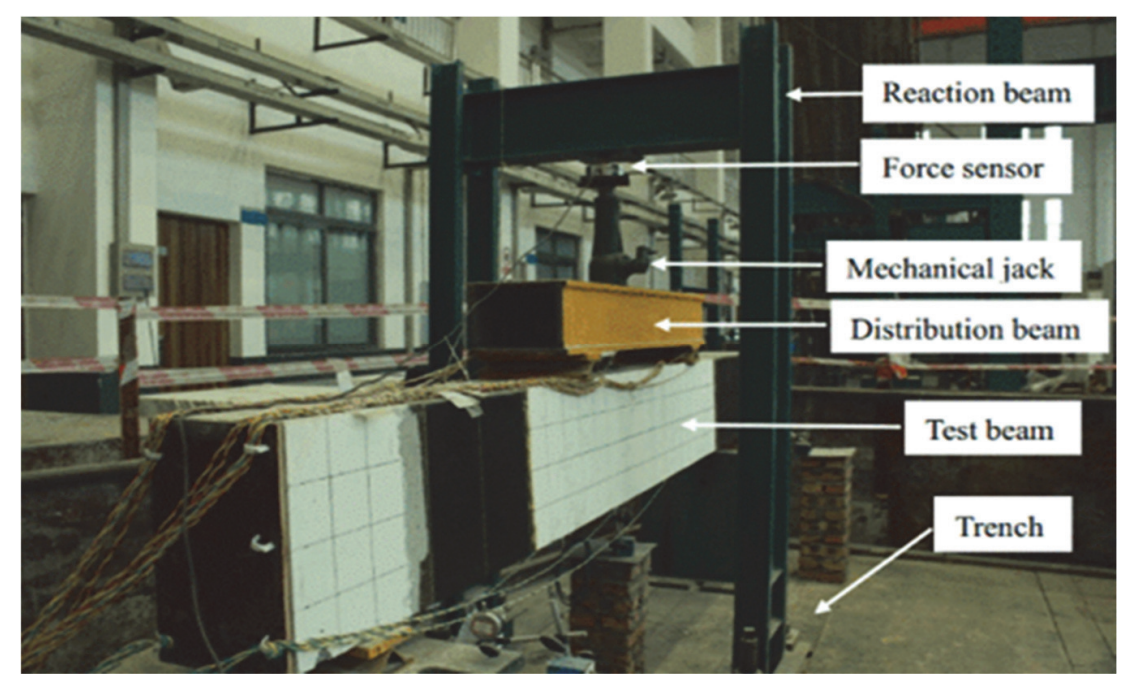

Figure 2: Loading device.

It can be seen from Tab. 1 that, with the increase of preload, the instantaneous midspan deflections of B-2, B-3 and B-4 were on the rise and the residual midspan deflections grew after unloading. Considering the crack development in Fig. 3 , it is clear that the B-4 had the most severe degree of cracking under the preload, followed by B-3 and B-2 in decending order. No cracks were observed in B-2 because of its low preload level (below the cracking load). The small preload-induced deflection, coupled with the lack of residual deflection, is insufficient to form a visible fracture. The cracking situation of B- 
2 is similar to that of B-1. After the pre-loading and unloading, the four test beams can be ranked as B-4> B-3> B-2 (B-1) by the cracking degree. Then, all the beams were reinforced as per the said plan.

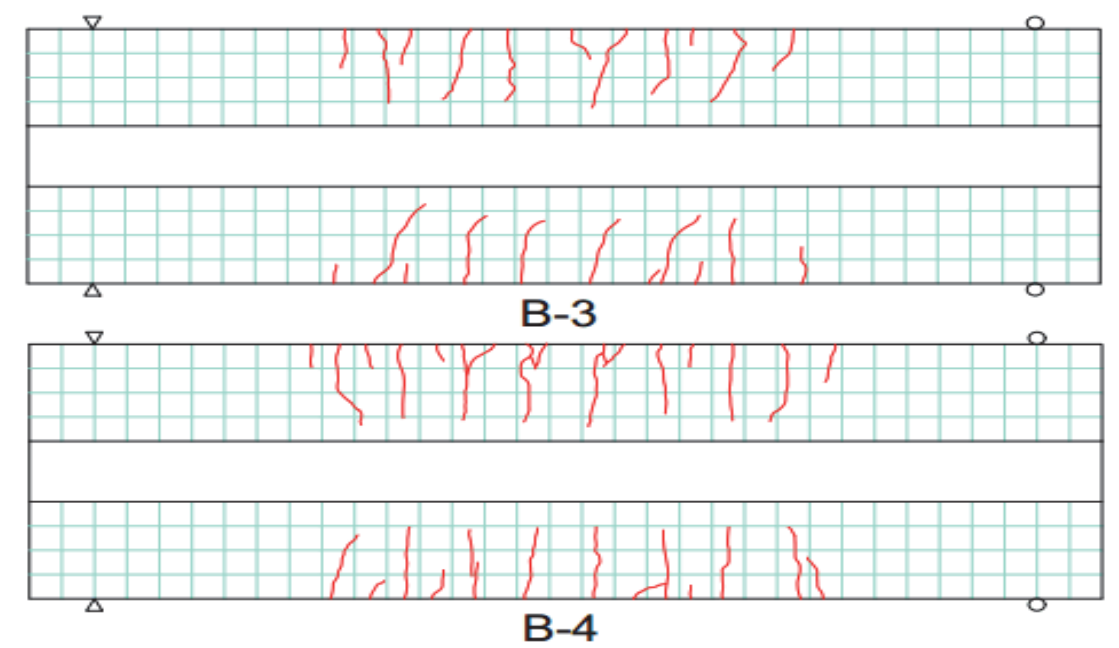

Figure 3: Cracks induced by pre-loading.

\begin{tabular}{cccc}
\hline & B-2 & B-3 & B-4 \\
Pre-load $(\mathrm{kN})$ & 23.54 & 70.63 & 102.02 \\
Deflection(mm) & 0.490 & 2.365 & 6.394 \\
Residue Deflection(mm) & 0.003 & 0.171 & 2.051 \\
\hline
\end{tabular}

Table 1: Midspan deflections of pre-loaded beams.

Short-term deflection and cracks

Tab. 2 records the midspan deflections of all beams under $75 \% \mathrm{Fu}(117.68 \mathrm{kN})$. The crack development under this load is presented in Fig. 4.

\begin{tabular}{ccccc}
\hline & B-1 & B-2 & B-3 & B-4 \\
Deflection $(\mathrm{mm})$ & 3.570 & 2.857 & 3.443 & 3.205 \\
\hline
\end{tabular}

Table 2: Deflection of static loading.

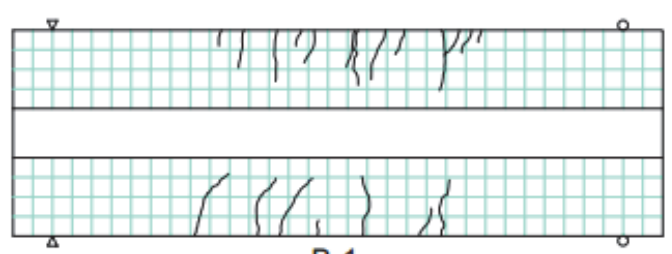

B-1

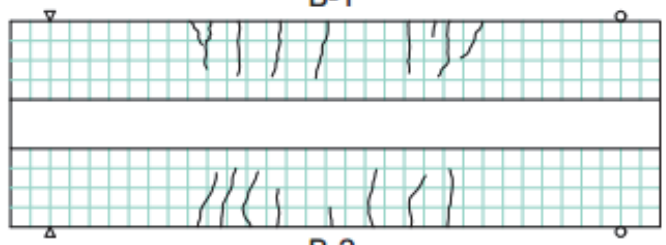

B-2

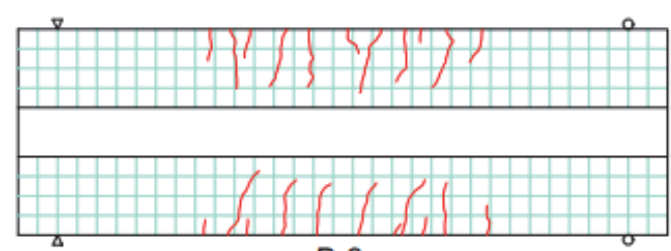

B-3

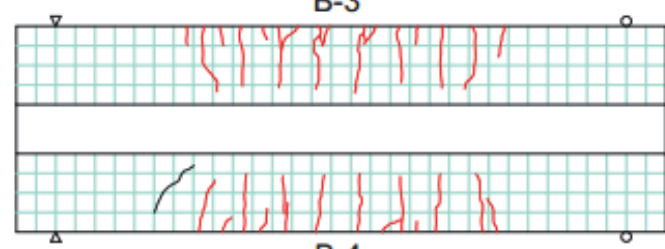

B-4

Figure 4: Cracks at the moment of final-loading.

As shown in Tab. 2, all four beams share similar instantaneous midspan deflections. The similarity can be explained as follows. The sectional stiffness of the test beams underwent similar amount of decrease despite the different degrees of 
cracks. Besides, the reinforcement both enhances the sectional stiffness and restrains the cracks after the CFRP enhancement. This partially offsets the negative effect of cracking on sectional stiffness. At the moment of loading, most tensile load was borne by the reinforced part, which further limits the crack development. That is why the pre-loading has an unobvious effect on sectional stiffness of reinforced beams in the short time. Of course, the initial stiffness of the test beams might not be exactly the same due to the discrete nature of the experiment (e.g. the casting quality of the beams). Under the above factors, there is no significant difference in instantaneous deflection among the four beams.

Fig. 4 shows the crack pattern of each beam at the moment of final loading. The red lines stand for pre-cracks, and black lines for the new cracked induced by the final load. It is clear that the instantaneous cracks under final load are all affected by the pre-cracks. The cracks on B-1 and B-2, which are intact beams, were all newly formed cracks, while no new crack was observed on B-3 and B-4, which are pre-cracked. The absence of new cracks on the pre-cracked beams is attributable to the near homogeneity of the pre-cracks. Furthermore, B-1 and B-2 had lower degree of instantaneous cracking and smaller crack spacing than B-3 and B-4. Under the action of pre-cracking and final loading, the four beams can be ranked as B-4> B-3> B-2 (B-1) according to the degree of cracking at final loading.

\section{Long-term deflection and cracks}

Temperature and humidity variation

The long-term test was conducted in lab at the mean temperature of $21.5^{\circ} \mathrm{C}$ and the mean humidity of $73 \%$. During the test, the temperature and humidity varied over time.
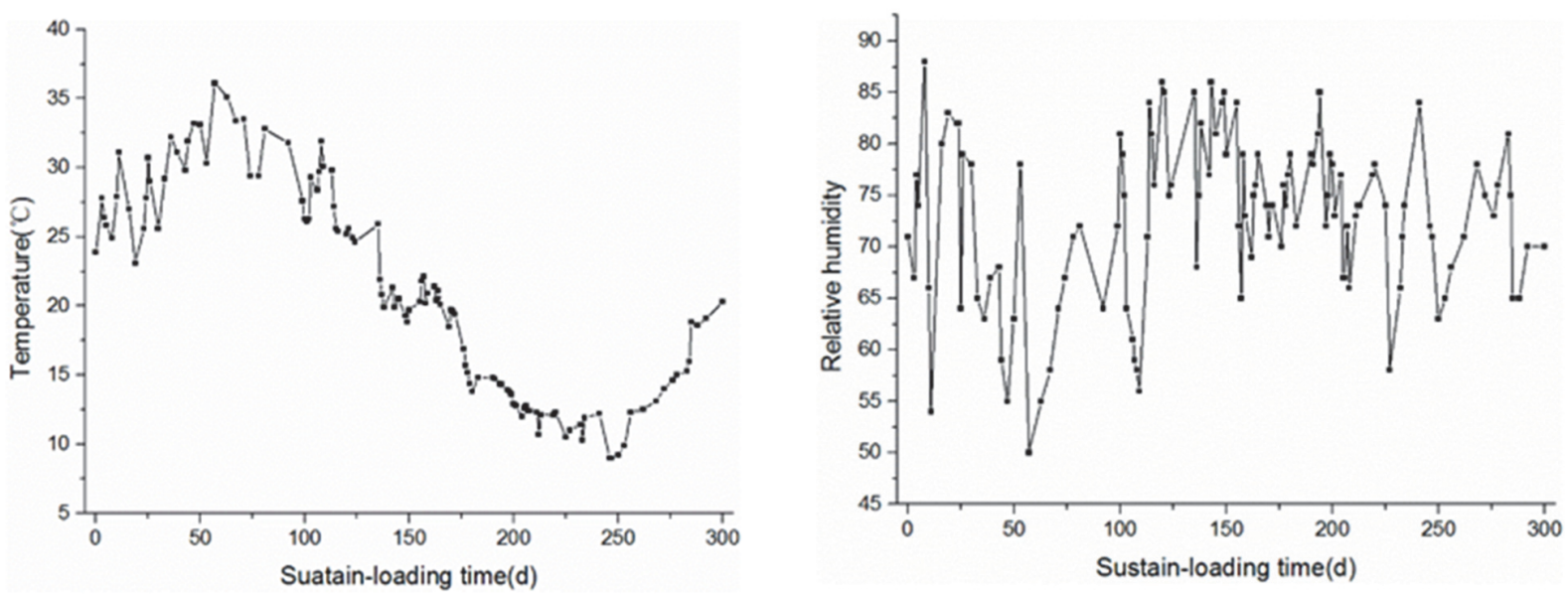

Figure 5: Test temperature and Relative humidity during the sustain-loading time

Long-term deflection

All the beams were subjected to a sustained and constant load for 300 days. During the period, the midspan deflection and crack development of each beam were recorded regularly (Figs. 6 8; Tab. 3).

\begin{tabular}{ccccc}
\hline & B-1 & B-2 & B-3 & B-4 \\
Immediate deflection(mm) & 3.570 & 2.857 & 3.443 & 3.205 \\
Total deflection(mm) & 5.636 & 4.771 & 5.140 & 4.578 \\
Additional deflection(mm) & 2.066 & 1.914 & 1.697 & 1.373 \\
Additional/Immediate $(\mathrm{mm})$ & 0.579 & 0.670 & 0.493 & 0.428 \\
\hline
\end{tabular}

Table 3: Deflection under sustain-loading time.

Tab. 3 lists the instantaneous midspan deflection of each beam (excluding the residual deflection after pre-loading and unloading), the total deflection and the additional deflection in the test period. As shown in the table, all reinforced beams underwent varied degrees of increase in deflection under sustained loading. After 300 days, the additional deflection of most beams reached almost half of the instantaneous deflection. That of B-2 even reached $67 \%$ of the instantaneous deflection. The additional deflection of B-2, B-3 and B-4 was respectively 7.3\%, $17.9 \%$ and 33.5\% lower than that of B-1. In the other 
case of the same conditions, B-1 and B-2 had almost no pre-cracking and little additional difference in deflection; B-4 had the largest degree of pre-cracking and the minimum additional deflection; B-3 had a medium degree of pre-cracking, and a medium additional defection (smaller than B-4 yet greater than B-1 and B-2).

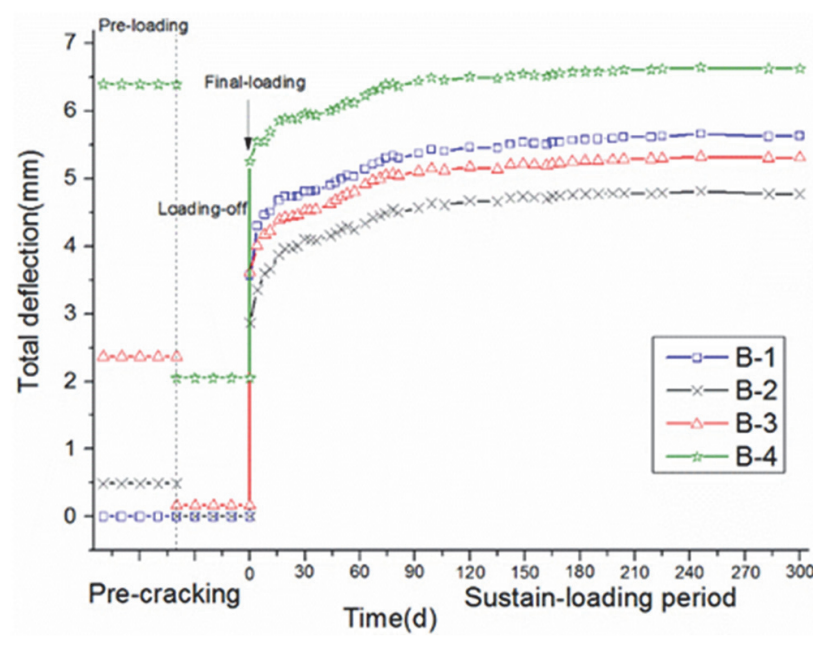

Figure 6: Long-term deflection under sustained loading.

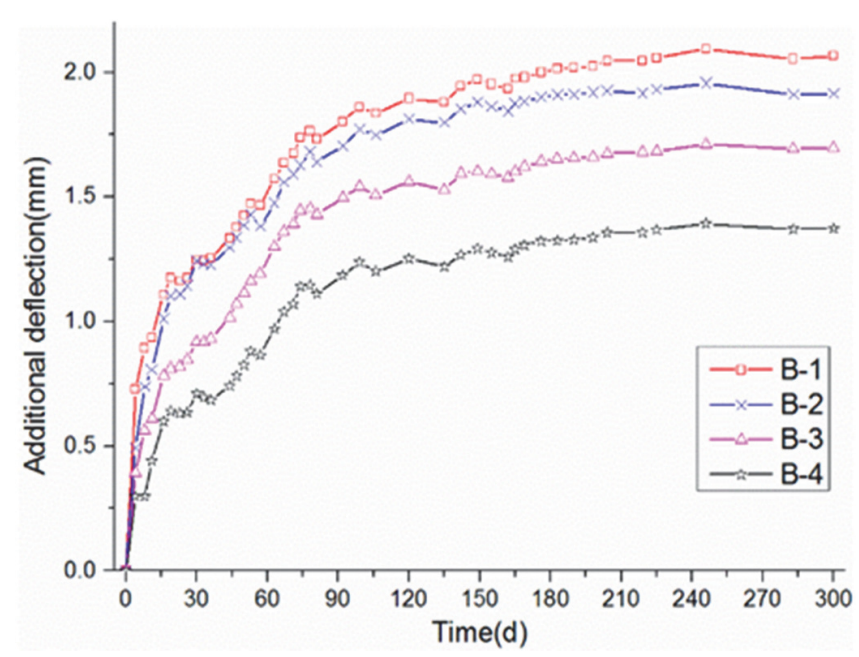

Figure 7: Additional deflection under sustain-loading.

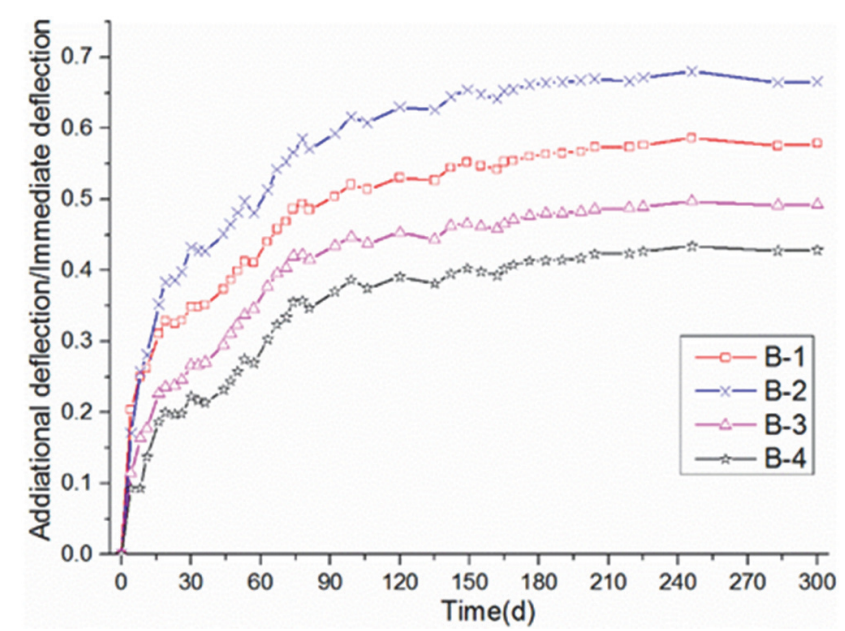

Figure 8: Ratio of additional deflection to immediate deflection. 
Fig. 6 displays the variation in midspan deflection of the beams during the pre-loading, unloading, final loading and sustained loading. It is clear that the total deflection of each beam is controlled by the instantaneous deflection. With a high preload, B-4 boasted a large residual deflection, a significant total instantaneous deflection, and the greatest final deflection; By contrast, B-2 exhibited a small total instantaneous deflection and the lowest final deflection, thanks to its small pre-load, residual deflection and final midspan deflection.

Fig. 7 presents the trend of additional midspan deflection in the test period. From this figure, it can be seen that, whatever the degree of pre-cracking, the long-term deflection always developed rapidly right after final loading and then slowed down to a stable state. In terms of magnitude, the additional deflection in the first 100 days was $90 \% \sim 92 \%$ of the total additional deflection in the test period, that is, most of the deflections occurred in the early phase. Under long-term load, the rate of deflection development varied with the degrees of pre-cracking. Overall, the degree of pre-cracking is positively correlated with the gentleness of the additional deflection curve and negatively with the increment of deflection.

Fig. 9 shows the relationship between the additional deflection and instantaneous midspan deflection in the test period. It is observed that the ratio increased with the degree of pre-cracking. During the 300 days, the ratios of B-1, B-2, B-3 and B4 were $57.9 \%, 67 \%, 49.3 \%$ and $42.8 \%$, respectively. The proportion of additional deflection decreased with the growth in the pre-cracking degree. This means the time variation of deflection is negatively correlated with the magnitude of deflection at final loading.

Considering the fluctuations of the deflection and the law of temperature and humidity (Figs. 5), the varied "anti-arch" degrees among the beams can be ascribed to the uneven shrinkage of concrete under the varying temperature and humidity. Nevertheless, the two factors no longer influenced the deflection trend in the later phase of the test.

Long-term cracks

Fig. 9 exhibits the crack development of each beam during load holding (excluding the pre-cracks and the instantaneous cracks at final loading).

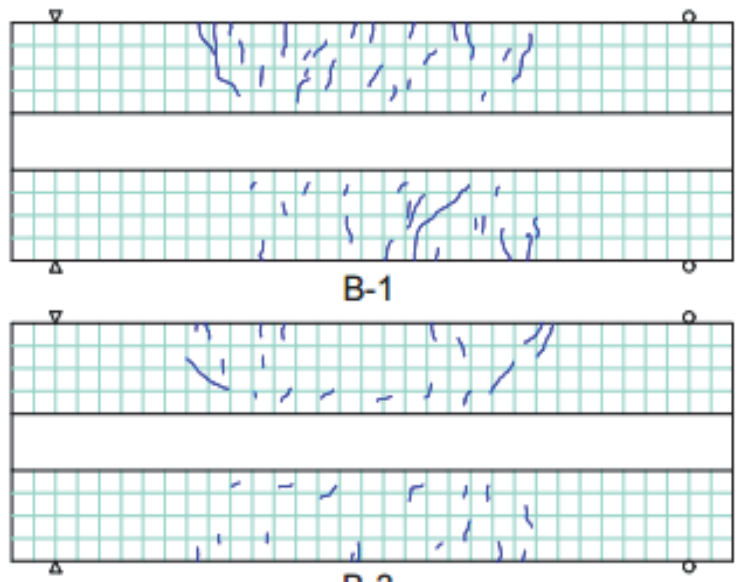

B-3

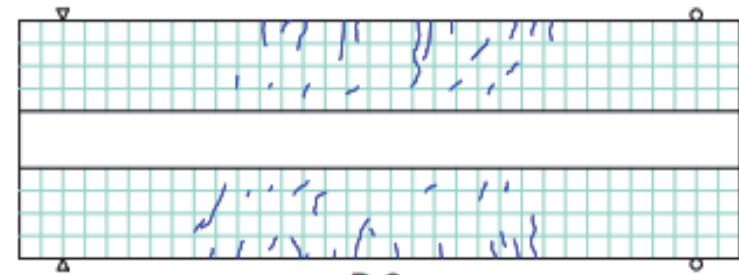

B-2

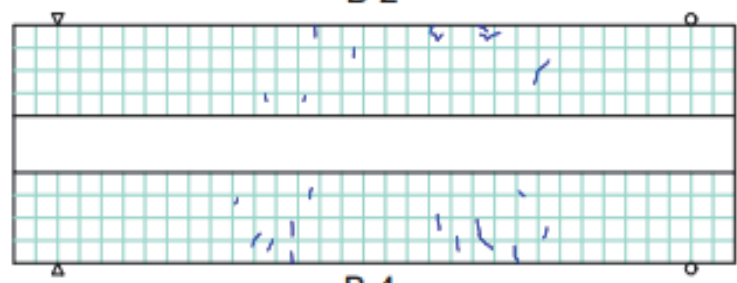

B-4

Figure 9: Cracks under sustained loading.

As shown in Fig. 9, most of the cracks developed on B-3 and B-4 during the load holding period were extensions of previous cracks. By contrast, there was a considerable number of new cracks on B-1 and B-2 besides the extended ones. In terms of crack quantity and height, B-1 and B-2 had much more new cracks than B-3 and B-4, indicating that the two beams were continuous cracked as the concrete reached the cracking strain under sustained load. B-3 and B-4 had fewer new cracks because the preload-induced cracks are relatively tall and the load during crack development was limited by compressive bars and concrete compression.

The concrete creeped at a fast rate in the initial phase, but the rate gradually slowed down to a stable state over the time. In the 300 days, the time-deflection curve became increasingly gentle, and the creep tendency of each beam had an obvious relationship with the additional deflection (Figs. 7 and 8). There was virtually no visible crack development from 100 to 300 days, meaning that the cracks had fully developed

The above results reveal the positive correlation between pre-cracking degree and the additional deflection after reinforcement. The relationship agrees well with that obtained by M. Muller [11] through relaxation tests on pre-cracked reinforced beams. 


\section{RESULTS ANALYSIS}

$\mathrm{U}$ nder the action of sustained load, the additional deflection falls into two parts: the deflection increment arising from concrete creep, and the deflection increment resulted from the decrease in sectional stiffness

\section{The deflection increment arising from concrete creep}

When a beam is under a sustained load, the creep of its material may magnify its component deflection over the time. Here, concrete is the main creep material of the test beams. Previous research [15] has shown that concrete is restricted by steel bars, supports and other components, and the deflection of reinforced beam is affected by the creep of both compressive concrete and tensile concrete. In the same conditions, a CFRP-reinforced beam faces more stringent restrictions (e.g. CFRP plates) than unreinforced beams. The additional restrictions have an impact on long-term deflection, especially when the beam is pre-cracked. The higher the degree of pre-cracking, the less concrete will creep under sustained loading. Hence, the additional deflection decreases with the rise of the pre-cracking degree. Meanwhile, a high degree of pre-cracking means lots of stress will be released and redistributed to steel bars and CFRP plates. In this case, the mean stress level of the concrete becomes smaller (Fig. 10), leading to a small creep. Therefore, the number of pre-cracks is negatively correlated with the long-term additional deflection.

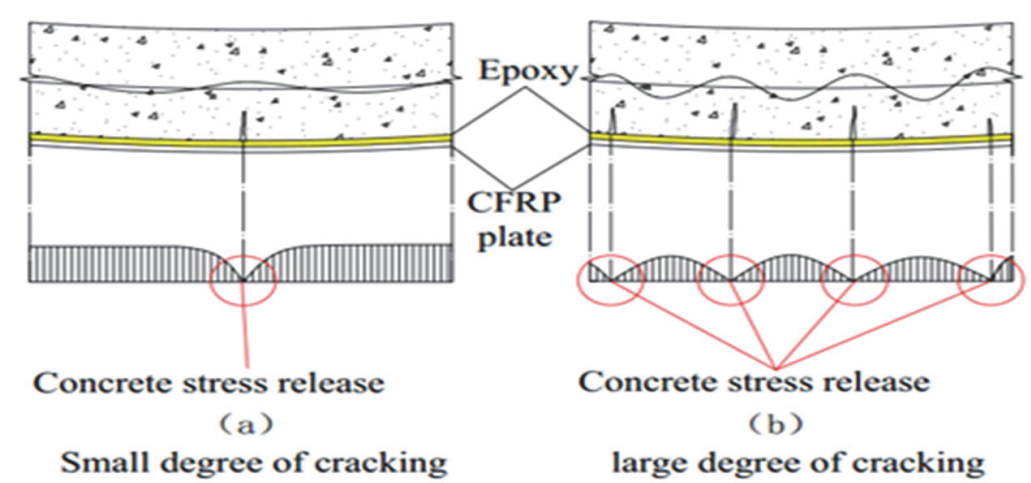

Figure 10: The stress distribution of tensile concrete under different pre-cracking degrees.

\section{Deflection increment resulted from the decrease in sectional stiffness}

With the decrease in sectional stiffness, there is an instantaneous increase in the deflection of the beams. Under the sustained loading, the bending stiffness of the beams will be reduced despite the constancy of the external load [16]. The stiffness reduction under sustained load can be explained by two main reasons: (1) the concrete shrinkage weakens the bond between the concrete and the steel bars; (2) the cracks continue to grow under sustained load.

The four test beams were made of the same concrete and steel, and casted at the same time. The experiment was carried out indoors in the same environment. Therefore, the four beams must have the same shrinkage and the same effect on sectional stiffness under sustained load.

Due to concrete creep, all beams undergo the increase in curvature and deflection. The underdeveloped cracks will grow in height. The height growth keeps reducing the sectional stiffness under sustained load and bolstering the deflection of components in the sustained loading phase until the crack propagation is restricted by compressive bars. In essence, concrete creep is the ultimate cause of the reducing sectional stiffness under sustained loading.

\begin{tabular}{ccccc}
\hline & Pre-crack & Immediate crack & Total-crack & Additional crack \\
\hline B-1 & -- & 3939 & 6862 & 2923 \\
B-2 & -- & 4024 & 6724 & 2700 \\
B-3 & 4276 & 4276 & 6403 & 2127 \\
B-4 & 6285 & 6989 & 7411 & 1125 \\
\hline
\end{tabular}

Table 4: Total height of cracks at different moment during the test $(\mathrm{mm})$. 
According to Tab. 4, the total crack height in the sustained loading phase is affected by the total height of pre-cracks. With no pre-cracks, B-1 and B-2 have greater height of cracks during sustained loading phase. With high total pre-crack height, B-3 and B-4 have limited growth in crack height in the same phase, leading to reduced sectional stiffness and surge in longterm deflection.

\section{CONCLUSIONS}

(1) The pre-cracking degree before reinforcement has little effect on the instantaneous stiffness of the reinforced beam, that is, the instantaneous beam deflection will not change much after the reinforcement. The total deflection of reinforced beam is controlled by the instantaneous deflection (including the residual deflection. The additional deflection accounts for a small proportion of the total deflection.

(2) The pre-cracking degree of before strengthening will affect the additional deflection of strengthened beams, the larger the pre-cracking degree is, the smaller the long-term additional deflection of the strengthened beam is.

(3) Concrete creep is the ultimate cause of deflection. The pre-cracking of concrete beam reduces the concrete viscoelasticity and releases the concrete stress, which in turn lower the concrete creep and additional deflection.

(4) The degree of pre-cracking is negatively correlated with the crack development under sustained load, the decline of sectional stiffness and the magnitude of additional deflection.

(5) The creep of concrete will cause the change of the long-term deflection and the cause of the long-term stiffness reduction of the strengthened beam, so the creep of the concrete is the most fundamental reason for the increase of the long-term additional deflection of the reinforced beam.

\section{ACKNOWLEDGMENTS}

he authors are grateful to the finical support from the Key Projects of College Outstanding Achievements Transformation (KJZH14220).

\section{REFERENCES}

[1] Pan, W. (2017). Application of carbon fiber reinforcement in structural strengthening engineering, Development Guide to Building Materials, 15(8), pp. 44-46.

[2] Ali, B.M., Bouiadjera, B.B., Chikh, E.B.O., Elmeguenni, M. (2017). The effect of the plastic instability on the behavior of an amorphous polymer, Mathematical Modelling of Engineering Problems, 4(1), pp. 53-58.

DOI: $10.18280 /$ mmep.040111.

[3] Hong, S. (2014). Effect of Intermediate Crack Deboning on the Flexural Strength of CFRP-Strengthened RC Beams, Mechanics of Composite Materials, 50(4), pp. 523-536. DOI: 10.1007/s11029-014-9439-6.

[4] Shuraim, A.B., El-Sayed, A.K., Al-Negheimish A.I. (2016). Efficiency of CFRP Strengthening in Controlling the Deflection of RC Beams in a Redundant Structural System, Journal of Composites for Construction, $20(2), 04015054$. DOI: $10.1061 /$ (ASCE)CC.1943-5614.0000604.

[5] Peng, H., Zhang, J., Shang, S. (2016). Experimental study of flexural fatigue performance of reinforced concrete beams strengthened with prestressed CFRP plates, Engineering Structures, 127, pp. 62-72. DOI: $10.1016 /$ j.engstruct.2016.08.026

[6] Plevris, N., Triantafillou, T.C. (1994). Time-Dependent Behavior of RC Members Strengthened with FRP Laminates, Journal of Structural Engineering, 120(3), pp. 1016-1042. DOI:10.1061/(ASCE)0733-9455(1994)120:3(1016).

[7] Hong, S., Park, S.K. (2016). Long-term behavior of fiber-reinforced-polymer-plated concrete beams under sustained loading: Analytical and experimental study, Composite Structures, 152, pp. 140-157. DOI: $10.1016 /$ j.compstruct.2016.05.031.

[8] El-Sayed, A.K., Al-Zaid, R.A., Al-Negheimish, A.I. (2014). Long-term behavior of wide shallow RC beams strengthened with externally bonded CFRP plates, Construction \& Building Materials, 51(4), pp. 473-483.

DOI:10.1016/j.conbuildmat.2013.10.055. 
[9] Tan, K.H., Saha, M.K. (2006). Long-Term Deflections of Reinforced Concrete Beams Externally Bonded with FRP System, Journal of Composites for Construction, 10(6), pp. 474-482. DOI: 10.1061/(ASCE)1090-0268(2006)10:6(474).

[10] Kim, S.H., Han, K.B., Kim, K.S. (2009). Stress-strain and deflection relationships of RC beam bonded with FRPs under sustained load, Composites Part B Engineering, 40(4), pp. 292-304. DOI: 10.1016/j.compositesb.2008.12.003.

[11] Muller, M., Toussaint, E., (2007). Investigation into the time-dependent behavior of reinforced concrete specimens strengthened with externally bonded CFRP-plates, Composites Part B Engineering, 38(4), pp. 417-428. DOI: 10.1016/j.compositesb.2006.10.001.

[12] Rao, X.P. (2006). Experimental study on the creep of reinforced concrete beams strengthened with carbon fiber cloth, Hunan University.

[13] Gilbert, R.I., Ranzi, G. (2010). Time-Dependent Behavior of Concrete Structures//Time-dependent behavior of concrete structures, Spon.

[14] Wang, X.G., Li, S., Zhou, X.G. (2014). Study on anti stripping of U type hoop in flexural strengthening of CFRP with weak interface, Journal of Civil, Architectural and Environmental Engineering, 36(2), pp. 14-20.

[15] Cao, G.H., Yang, L., Zhang, K.C.H. (2017). Influence of reinforcement on creep of concrete, Journal of Central South University (Science and Technology), 48(2), 506-511.

[16] Zhu, P.H., Chen, C.H. (2013). Design principle of concrete structure, Beijing Institute of Technology Press. 